\title{
Structuring of Self and Twinship
}

\author{
F. Castellet y Ballarà, E. Bollea \\ Department of Psychiatric Science and Medical Psychology, University of Rome "La Sapienza", \\ Italy
}

\begin{abstract}
Latest psychoanalytical research, based on the integration of the geneticreconstructive method and the observative-developmental one, points out that twinship presents specific difficulties in the structuring of Self. The unfavourable feature in the structuring of Self in twins is the sharing of the mother from the very beginning of intrauterine cohabitation passing to the relative deficiency of primary maternal care. The clinical cases of two adult DZ twins under psychoanalytical - psychotherapy treatment are herein reported to emphasize: the defective formation of a sense of personal identity; the high recurrence of cross-projective identifications; and, the tendency to assume complementary roles and re-create bonds and relationships similar to the ones experienced with the cotwin. Within the therapeutic relationship, the following features come to light: the unconsciously fantasized presence of the other twin; the strong feelings of self depreciation, inability and angry emptiness. These feelings seem to enhance an adhesive transference, presenting difficulties in separating, strong ambivalence and fantasies of a continuous analysis with the analyst-twin. In the cases we report, the twin pair relationship with its dynamics, bound to the incomplete or defective structuring of Self, represents the essence of the relationship between the twin and the object.
\end{abstract}

Key words: DZ twins, Psychoanalytical psychotherapy, Self, Cross-projective identifications, Psychosis

\section{INTRODUCTION}

Psychoanalytical studies on the suffering of man's internal and deeper life experience have recently been enriched by the contributions of developmental psychology.

Studies in this field [9] demonstrate that even from the very first months of life, a twin infant is able to make subtle sensory discriminations and to grossly differentiate itself from its cotwin. 
In psychoanalysis, "infant observation" studies [5] confirm that, in the process of normal development, twins are conscious of being two separate individuals from about the third month of life. They also experience, earlier than singletons, the exclusion from the mother due to the presence of a rival. Singletons only face such an event when a sibling is born and its impact is somewhat reduced by the difference in age. Therefore, if the relationship with the primary object, ie. the breast/mother, is essential for the structuring of the infant's Self, in twins the presence of the cotwin strongly and continuously interferes with this primary relationship, from the beginning of intrauterine cohabitation. Possibly, from this defective condition in the early relationship with the mother derive the psychopathological patterns often observed in twins and referred to as an incomplete, or absence of, structuring of Self in terms of the individual entity. According to Kohut's definition, Self is intended as a structure of interpersonal genesis provided with Ego, Es and Super-Ego functions [7].

From a clinical perspective, disorders of Self promote early and frequent crossprojective identification mechanisms with the other twin [10] and these emerge in the following patterns. Twinship symbiosis [4], where there is a strong distortion of the individual's personality development to the advantage of the twin-couple personality, accompanied by omnipotent fantasies of self-sufficiency and invincibility. Twinship parasitism [2], where, due to a different development during the first year of life, as a result of illness or because of the unconscious refusal on the mother's part, etc., one twin develops a better control over his internal object-relationships compared to the other twin. In this case the weaker twin can only bear separation from the real object, ie, the mother, by referring to the more secure twin. The anxiety of a twin split in Self or the loss of half Self [3] is characterized by a painful feeling of incompleteness, which causes the object-relation disorders we observe in some monozygotic (MZ) twins, that can be expressed in the following terms: "if I get very close to someone or he gets too close to me, then he becomes my twin and takes away a part of me". Complementarity [8] consists in a strong ambivalence towards the object and in the avoidance of all situations which can stir rivalry up again. While the assumption of complementary roles within the pair determines a steady relationship, it also dictates rigid and definite roles for the Self, to the detriment of a true individualization.

\section{CASE HISTORIES}

We report the case histories of two DZ twins under psychoanalytical-psychotherapy treatment. The first patient is the second born of two 24-year-old female twins. Both are receiving treatment for a mixed psychosis that manifested itself after the death of their mother. The unconsciously fantasized presence of the cotwin comes to the surface from the very first sessions. The patient voices her wish that her sister be also present by immediately calling the therapist by name, by expressing fascination for his hair, remarking "beautiful like my sister's, whereas mine is curly and ugly", and by showing a photo of her sister. In the transference the therapist is unconsciously experienced as the other twin. During the sessions, expressions of hate and anger towards others e.g. the sister, the cotwin, the father and continuous demands for reassurance on hypochon- 
driacal fears, alternate. The difficulties and sense of depreciation which emerge during therapy probably arise from the strongly ambivalent need to establish a twinship relationship.

At the last session before summer holidays, the patient arrived very late, accompanied by her twin, who seated herself in the waiting room. Nevertheless, it seemed that the twin waiting outside was present in the office. The patient refers her twin's thoughts which stress and strengthen the symbiosis and identity confusion: "we both suffer for our mother's absence - I take pills, you sleep in order not to see"'.

The second case is a 35-year-old dizygotic male twin who has been diagnosed as having a chronical residual schizophrenia. The first symptoms appeared about ten years before, when in his fourth year of medical school, he gave up his studies. He was referred to the therapist by his twin brother, an engineer, who recently married and who is affected by a slow-growing brain tumor. Also in this case, the twinship theme comes immediately to light: from the very first sessions the patient again experiences through transference the ambivalent bond which unites him to his twin. The brother's recent marriage is still painfully present and not yet worked through: the patient feels abandoned, and is jealous of his sister-in-law, just as he had been jealous of his mother when he was a child. His relationship with women is very ambivalent and is characterized by keeping his distance either through idealization or devaluation. When he is invited to think over his illness, he says: “I am ill because I am a twin, I shouldn't have been a twin... my brother has always been the best, he is superior to me". Rivalry and competition are the main themes; his academic failure caused such injury to his amour-propre that he finds consolation in self-delusion: "I am a doctor and a specialist", he declares from time to time. His mother and twin brother are the only people he thinks about when he feels lonely and uneasy. Confusion is evident in his depressive states, and he experiences anxieties regarding the subject of death, which for him expressly means separation from his mother and brother: "if I die my brother will be sorry, whereas if he dies I will be sorry".

\section{DISCUSSION AND CONCLUSION}

Psychoanalysts often consider DZs as 'just brothers', while inferring that only MZs may suffer psychological consequences arising from twinship. In our opinion, twinship is best described in terms of the effects of primary maternal co-sharing on the structuring of Self. Furthermore, we agree with some authors $[1,6]$ that the presence of an identifying reference figure, as an alternative to the mother and cotwin, is an essential cofactor for the development of a twin's individual structuring of Self. The structuring of Self may be incomplete or defective in one twin but not necessarily in both. In the cases we examined, disorders of Self are prominent and when in a depressive state the feelings of self-depreciation, uselessness and angry emptiness are magnified. In the first case, the frequent references to the body (e.g. hair, face etc.), indicate the difficulty in keeping distinctly intact the body image, or somatic Self, which seems to be continuously at risk of merging into that of the other twin. In the second case, the delusive pathophobic and thanatophobic inferences seem to represent the mental equivalence of the brother's 
brain tumour, as though for a twin the structuring of a separated Self necessarily involves a deadly risk.

To sum up, the immediacy with which, through transference, the other twin is brought into the session, represents the dynamics of cross-projective identifications and an unconscious complementarity which highlight a structuring of Self as a pair rather than as a single individual.

\section{REFERENCES}

1. Athanassiou C (1986): A study of the vicissitudes of identification in twins. Int J. Psycho-Anal vol. 67:329-335.

2. Athanassiou C (1991): Construction of a transitional space in an infant twin girl. Int Rev of Psycho-Anal vol. 18:53-63.

3. Calvesi A (1979): Angoscia di scissione gemellare del Sé o angoscia di perdita di una metà del Sé in una gemella monovulare. Riv Psicoanal, I:38-49.

4. Costantini MV, Mondino C, Munari F (1987): Il gemello, una simbiosi. Emergenza e strutturazione del Sé. Riv Psicol Clinica 2:215-226.

5. Davison S (1992): Mother, other and self-love and rivalry for twins in their first year of life. Int J Psyco-Anal 19:359-374.

6. De Astis A (1989): Relazione nevrotica infantile nella coppia gemellare in funzione del rapporto di coppia genitoriale. In Giannotti A \& G De Astis G (eds): II diseguale. Borla.

7. Kohut H (1984): How Does Analysis Cure? Chicago, Ill.: University of Chicago Press; Ital. trad. 'La cura psicoanalitica'. Boringhieri, 1986.

8. Stella $S$ (1989): Note su alcuni processi d'individuazione in gemelli adulti non-identici. In Valente Torre L (ed): I gemelli: il vissuto del doppio, Firenze: La Nuova Italia Ed. pp. 139-148.

9. Stern DN (1985): The interpersonal world of the infant. New York: Basic Books.

10. Turillazzi Manfredi S (1985): L'Unicorno: saggio sulla fantasia e l'oggetto nel concetto d'identificazione proiettiva. Riv Psicoanal 31 (4):462-477.

Correspondence: Dr. Francesco Castellet y Ballarà, Viale dei Colli Portuensi 122, 00151 Rome, Italy. 